\title{
Characteristics of Air Temperature and Humidity on Deserts and Oases at Turpan and Dunhuang in China
}

\author{
Akira TAKEMASA*, Taichi MAKI* \\ Kazuhiko OHBA $^{* *}$ and Yoshitaka KUROSE ${ }^{* *}$ \\ *Graduate School of Bioresource and Bioenvironmental Sciences, University of Kyushu Fukuoka, 812-8561 \\ Japan \\ **Department of Agro-Environmental Management, National Agricultural Research Center for Kyushu \\ Okinawa Region, Kumamoto, 861-1192 Japan
}

\begin{abstract}
According to the variation of the air temperature and humidity measurements, an interesting tendency on the oasis was observed. From the results of observation at Turpan, air temperature from daytime to evening hardly varies on the desert; however, it showed that air temperature suddenly decreased on the oasis. On the other hand, the peak of absolute humidity was observed at the oasis in the evening. During the next year, the same observations were carried out at Dunhuang. It also showed a result of the same tendency. This is also considered to be a unique phenomenon on other oases. In addition, the observations were also carried out in autumn. The variety of the occurrences autumn was less than in summer. However, they also showed same tendency. This is considered to occur in all seasons except winter.
\end{abstract}

Key words: Absolute humidity, Decreased temperature, Desert, Oasis

\section{Introduction}

An oasis surrounded by dry desert protects crops from harsh meteorological environmental factors such as from detrimental heat, dryness, and high dust concentration. An oasis also serves as a residential district for people and livestock. For the expansion of an oasis by greening and farming, it is very important to know the climatic characteristics of oases in an arid land. Thus, an investigation was carried out to analyze oasis climatic characteristics at Turpan and Dunhuang, China.

\section{Materials and Methods}

Using a mobile observation method, horizontal variations of air temperature and humidity were measured along routes through an oasis to a desert. Routes of mobile observation are shown in maps of Turpan and Dunhuang. (Figs. 1. and 2.) Observations were carried out at Turpan on September 13, 14 and 15, 2002, at Dunhuang on August 3, 4 and 5, and on October 5, 6 and 7,2003. Times of mobile observation started from early morning, morning, early afternoon, late afternoon until evening. It was fine weather during these days.

Instruments were set on the roof of the car (heights of $1.4 \mathrm{~m})$. Air temperature and humidity were measured every 10 seconds, with the car at a constant speed of $30 \mathrm{~km} / \mathrm{h}$. Times were recorded at every $1 \mathrm{~km}$, and the present location was confirmed. In addition, instruments were set at fixed points in the oasis and desert, air temperature and humidity were measured, and air temperature correction was made because there was a possibility of meteorology change with the passage of time.

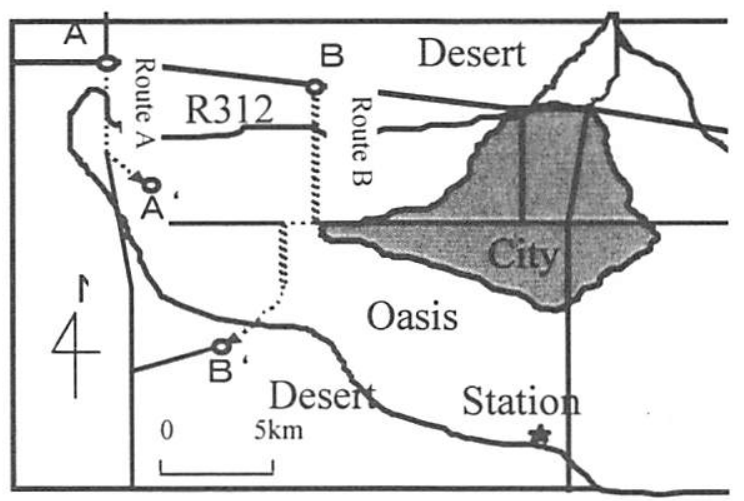

Fig. 1. Map of the observation field in Turpan

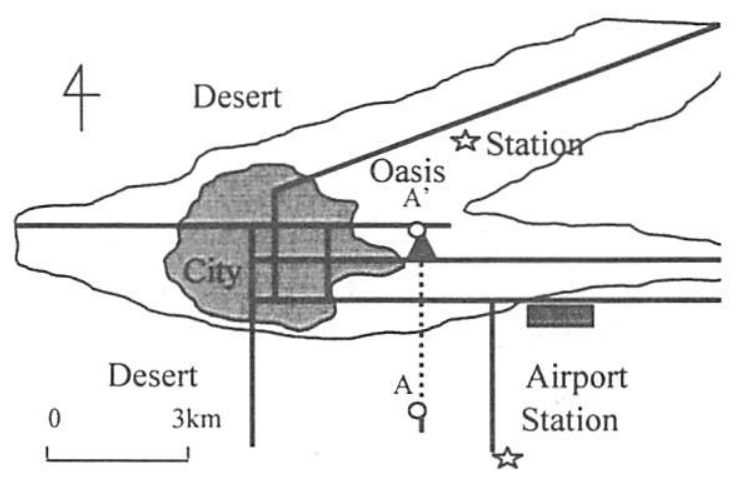

Fig. 2. Map of the observation field in Dunfuang. 


\section{Result of observation}

\subsection{Result of observation at Turpan}

Figs. 3. and 4. show the air temperature and absolute humidity in early afternoon (17:00-17:12, BST) and late afternoon (18:49-19:01, BST) on September 13, 2002. (Route A, Fig. 1) From early afternoon to late afternoon, the air temperature decreased only about $0.5-1^{\circ} \mathrm{C}$ on the desert; however, it decreased about $3.5^{\circ} \mathrm{C}$ on the oasis. As to absolute humidity, it remained the same value on the desert. On the other hand, it suddenly increased on the oasis.

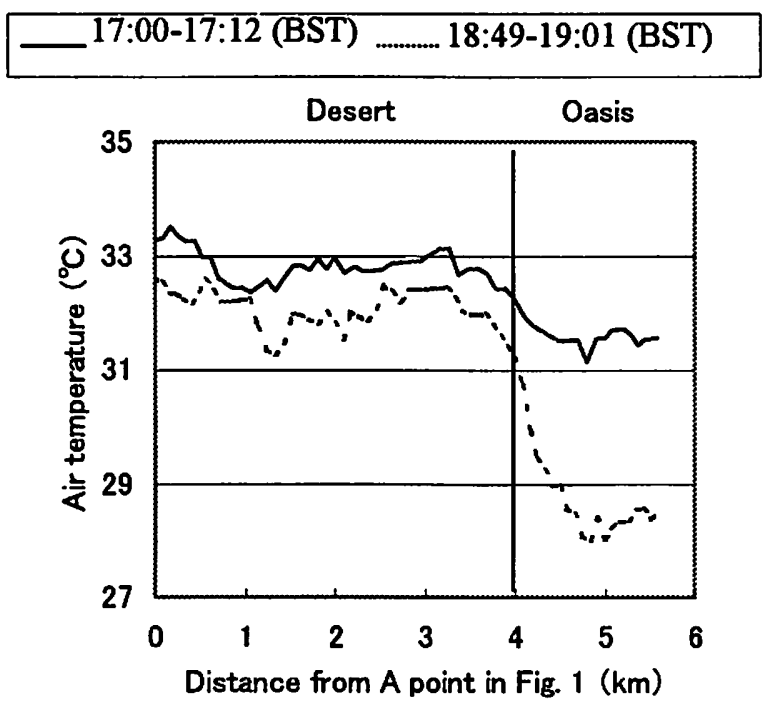

Fig. 3 Variation of air temperature on September 13, 2002

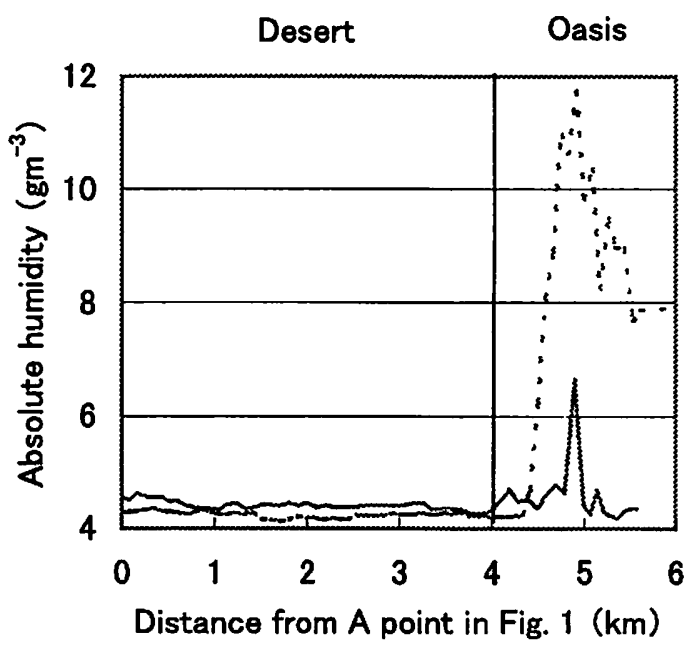

Fig. 4 Variation of absolute humidity on September 13, 2002

\subsection{Result of observation at Dunhuang}

Figs. 5. and 6. show the air temperature and absolute humidity in early afternoon (15:34-15:47, BST) and late afternoon (19:20-19:31, BST) on August 4, 2003. (Fig. 2) From early afternoon to late afternoon, air temperature decreased about $1^{\circ} \mathrm{C}$ on the desert; however, it decreased about $4-5^{\circ} \mathrm{C}$ on the oasis. As to absolute humidity, it remained the same value on the desert. On the oasis, it increased about twice in value. Air temperature and absolute humidity hardly varied on the desert; however, it can be seen there was a trend for a suddenly decreased air temperature and increased absolute humidity from early afternoon to late afternoon on the oasis. This is the same as the result of the observation at Turpan.

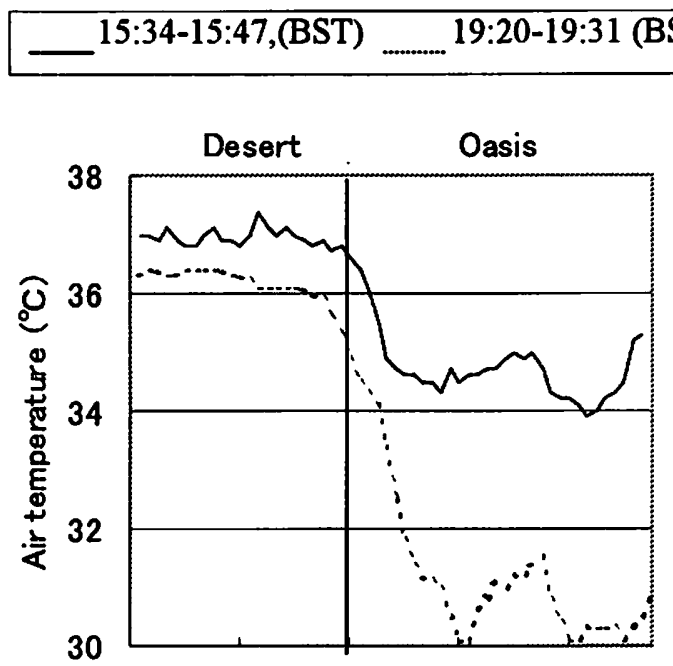

Distance from A point in Fig. $2(\mathrm{~km})$ Fig. 5 Variation of air temperature on October 4, 2003

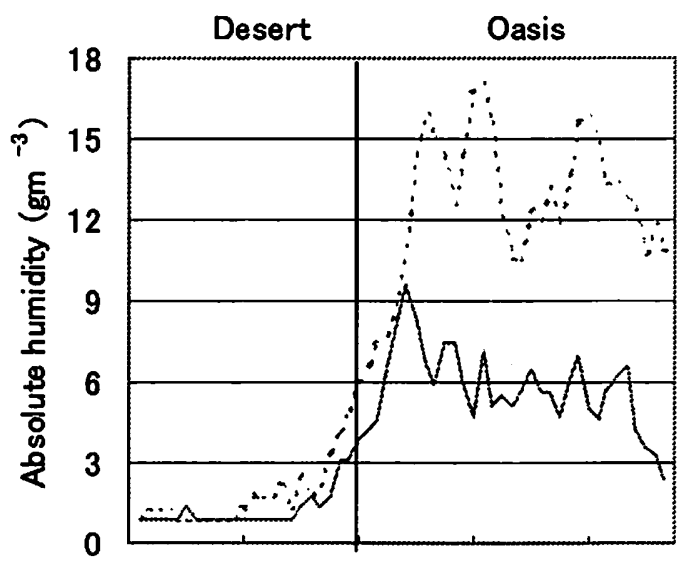

Distance from A point in Fig. $2(\mathrm{~km})$

Fig. 6 Variation of absolute humidity on October 4, 2003 


\section{Discussions and Conclusions}

It can be seen that there is a trend for a suddenly decreased air temperature and increased absolute humidity from daytime to evening on the oases at Turpan and Dunhuang. This is considered to be a unique phenomenon on other oases also. The variety in autumn was less than in summer; however, it showed same tendency. This is considered to occur at all seasons. But the difference can be hardly seen because vegetation on the oasis withers in winter.

Some reasons are considered that physiological factors such as vegetation on the oasis or meteorological factors cause that trend. However a condition like this was reported before. 「 A Significant Evening Peak of Vapor Pressure at an Oasis in the Semi-Arid Region」 (Tsukamoto etc). In this paper, it was reported that significant evening peaks were observed in the diurnal variations of vapor pressure over an oasis surrounded by desert in the northwest part of China. According to the surface flux measurements and the upper air soundings measurements, the following hypothesis was suggested.

The daytime hot and dry air was observed over the oasis on fine days in summer. This means that convective mixing is much stronger and transports much more water vapor in the oasis upper layer than in the lower layer. It is considered that the water vapor supply from the surface due to evapotranspiration is not enough to keep the vapor pressure constant during the daytime. In the evening, the decay of convective turbulence can lead to smaller water vapor flux in the upper layer. However, evapotranspiration still continues upward and leads to a water vapor flux convergence near the surface.

This hypothesis can explain the increased humidity; however, it is inadequate at explaining the decreased air temperature. There may also be other meteorological factors. It is necessary to investigate local meteorology and heat balance etc. There is an instance of mid-day depression of photosynthesis. And it may be one of the reasons. It is considered that meteorological factors and physiological factors of

\section{References}

Kurose, Y., Tang, L., Ohba, K., Maruyama, A. and Maki, T., 1998: Variations of Air Temperature and Relative Humidity from a Desert to an Oasis in Turpan, China, J. Agric. Meteorol., 54(4), 337-343

Tsukamoto, O., Wang, J. and Mitsuta, Y., 1992: A Significant Evening Peak of Vapor Pressure at an Oasis in the Semi-Arid Region, J. Meteor. Soc. Japan, 70, 1155-1160 